\title{
Reproductive Periodicity, Fecundity and Sex Ratio of Goldfish Carassius auratus (Perciformes: Cyprinidae) Under Laboratory Condition
}

\author{
Ruhul Amin, Farida Mazumder, Akhtar Nargis, Mahmuda Khatun and \\ Debashish Talukder \\ BCSIR Laboratories, Binodpur Bazar, Rajshahi-6206, Bangladesh
}

\begin{abstract}
The present study showed that Carassius auratus, breeds within September to March in freshwater and laboratory condition. It is a single breeder and highest percentage of gravid female occurs in December (87.5\%). The GSI and GLI ranged from 2.43 to 8.0 and 2.38 to 25.03 respectively. Both GSI and GLI were highest in December (8.0) and (25.03) but lowest value of GSI was in September and GLI was in August. The

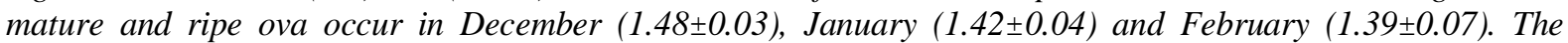
relationship between fecundity and total length; fecundity and body weight; fecundity and ovary weight were $11545+1066 x, r=0.64 ;-62418+2402 x, r=0.87$ and $-11494+13 x, r=0.99$ respectively.
\end{abstract}

Keywords: Ornamental fish, fecundity, GSI, GLI

\section{Introduction}

Nurturing Carassius auratus, the first of ornamental or live jewels organism, is one of the oldest and most popular hobbies in the world for ornamental fish lovers. This fish species is benthopelagic, non-migratory and omnivorous living in fresh and brackish water [1]. C. auratus are known to have a moderately long life span, with average duration of 6-7 years [2].

In Bangladesh the trade of ornamental fish is confined to its own territory till now [3]. The largest importer of ornamental fish is the USA followed by Europe and Japan. The emerging markets are China and South Africa.

There have been wide variety of research works done on various aspects of Carassius species worldwide $[4,5,6,7,8]$. In Bangladesh, there has been only one work done so far which focused only on induced breeding, embryonic and larval development of Carassius auratus [3], but no work has been done on reproductive periodicity, fecundity and sex ratio under laboratory condition in the country. So, an attempt was made to determine their reproductive periodicity, fecundity and sex ratio under laboratory condition.

\section{Materials and Methods}

A total of 428 fish were collected from local market, Rajshahi, from January, 2011 to December, 2012. The fish were collected monthly, and cultured in aquarium $\left(2^{1} 2^{\prime} \times 1 \frac{1 / 2^{\prime}}{} \times 2^{1 / 2^{\prime}}\right)$. The total length (TL) and body weight $(\mathrm{BW})$ were taken to the nearest $(\mathrm{mm})$ and $(0.01 \mathrm{~g})$ respectively. The $\mathrm{pH}$ value ranged from 7.8 to 8.3 and temperature of the water was from 9.5 to $28^{\circ} \mathrm{C}$. The ovaries were dissected out intact and their lengths and weights were taken. Excess moisture was removed from the surface of the fish as well as from the ovaries with blotting paper before their weight was taken. Sexes were distinguished by comparing shape of the body and abdomen.

Following methods were applied for the study of the reproductive cycles:

(1) Percentage of the gravid females against female

(2) Gonado-Somatic Index (GSI)

(3) Gonadal Length Index (GLI) and

(4) Diameter of the ova

(5) Coloration of gonad

Fecundity was estimated by the gravimetric method by [9]. Diameter of the ova was measured randomly from anterior, central and posterior region of the ovary with the help of ocular micrometer. The spawning period was estimated from the gonad development, Gonado-Somatic Index (GSI), Gonadal Length Index (GLI), direct observation of the gonads and monthly variations of individuals in different maturity stages [10]. 


\subsection{Reproductive Periodicity}

\section{Results and Discussions}

To determine the reproductive cycle five methods were used in this present study.

\subsubsection{Percentage of the gravid female against time}

The data obtained from 136 mature females of $C$. auratus reveal that the gravid female occurs from September to May. It is observed from Fig. 1 that in the month of December the percentage of gravid females was the highest $(87.5 \%)$ followed by January $(80 \%)$, February $(77.78 \%)$ and November $(69.23 \%)$. The result showed that reproductive strategy of this species was that individuals of different length groups spawn at different times, and spawning season extended from November to March. Spent fish first appears from April to May where they formed $22.22 \%$. No gravid female was found during the months of June and July.

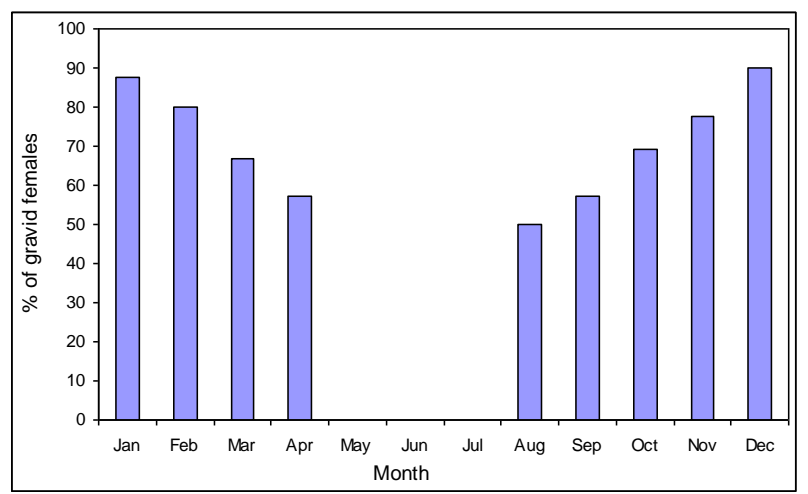

Fig. 1. Monthly percentage of gravid females of $C$. auratus

\subsubsection{Gonado-Somatic Index (GSI)}

Higher values of Gonado-Somatic Index were observed during December to April (Fig. 2) which indicated the breeding season of the fish. The values of the GSI showed single peak distinctly in the month of December. The GSI value was found to be low from May and the lowest value was found in the month of September which started to increase gradually from October indicated the onset of maturation. The mean GSI for 12 months ranged from 2.43 (September) to 8.0 (December). The fluctuation in GSI value coincided with proportion of fish in the different maturity stages to determine the spawning season.

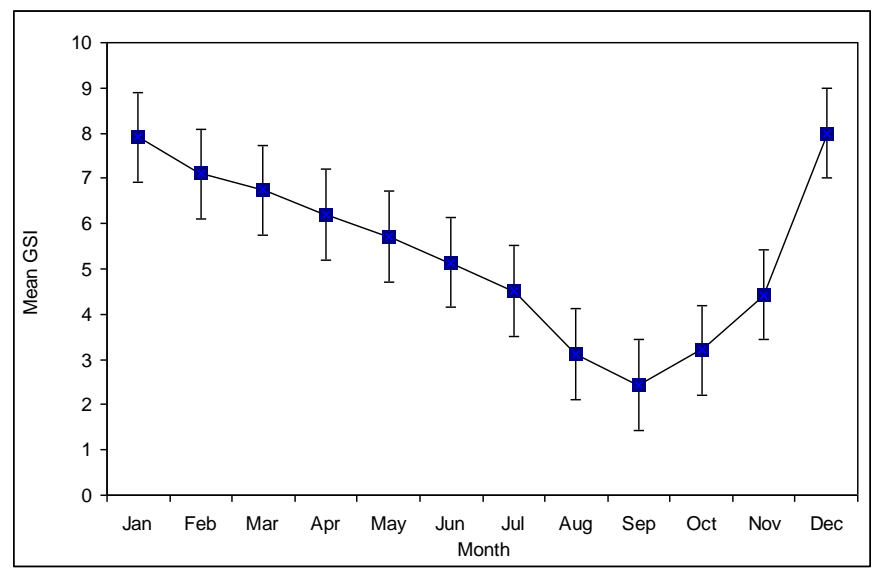

Fig. 2. Monthly mean Gonado-Somatic Index of C. auratus

\subsubsection{Gonadal Length Index (GLI)}

The variations of Gonadal Length Index due to variable condition of gonad for 12 months are given in Fig. 3. A single peak in the month of December indicates single breeding season of the fish. The maximum mean value was 25.03 for the month of December and minimum mean value was 2.38 for the month of August. Higher values of GLI were also observed during December, January and February. 


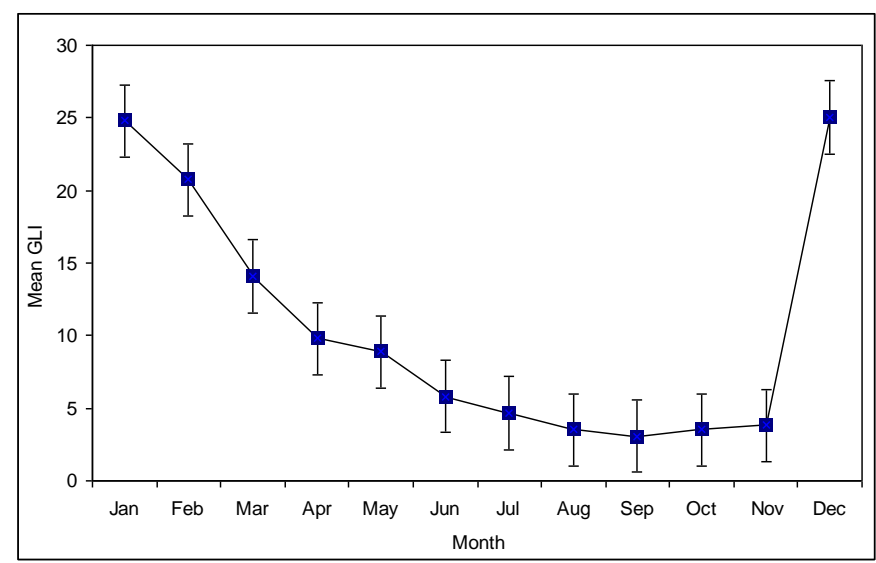

Fig. 3. Monthly mean Gonadal Length Index of C. auratus

\subsubsection{Diameter of the ova}

Ovum size may be used as an indicator of the spawning period in fishes [11]. The mean of the month wise average diameter of ova varied from 0.03 to $1.55 \mathrm{~mm}$ during the period of six months (from October to March) except June to August. It was observed from Fig. 4 that the fish had a single-spawning season extending from October to March having a peak in December. In December, January and February the mean and s.d. are $1.48 \pm 0.03,1.42 \pm 0.04$ and $1.39 \pm 0.07$ respectively. The number of mature and ripe females was found more in these three months than the other months and during June to August no mature female was noted.

\subsubsection{Coloration of Gonad}

The color changes of the ovary of a species depend on the degrees of the maturity of the ova. In the immature stage of gonad, the color is whitish in C. auratus and the ovary is transparent. Gradually the color becomes more intense and bright with the attainment of the maturity.

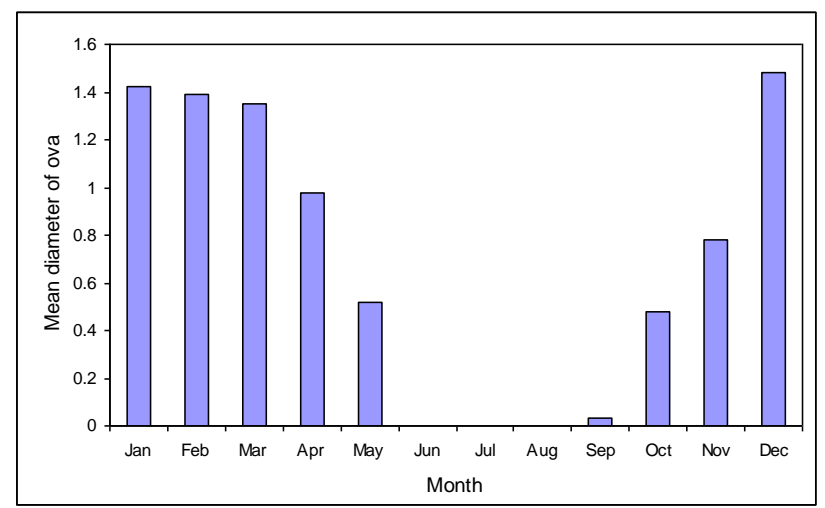

Fig. 4. Monthly mean ova diameter of C. auratus

In $C$. auratus, the immature ova are white in color and the ripe ova are reddish orange to orange in color. With the start of maturation the color of the ovary begins to change from white through pale yellow, light orange, orange and lastly to reddish orange or deep orange. In the months of December, January, February and March most of the females were provided with a deep orange ovary, indicated the ripeness of the ovary and active breeding months.

\subsection{Fecundity}

Only fish with well developed ovaries were used in the determination of fecundity, details on the fecundity are given in Table 1 . This table indicated that the number of eggs produced per fish varied widely within nearly the same length. Specimens examined ranged in length from 123 to $150 \mathrm{~mm}$ and weight from 30.5 to $43.2 \mathrm{gm}$. The eggs produced per female ranged from 9386 to 38950 .

Fecundity was related here to different parameters of the fish, namely total length (TL) (Fig. 5), body weight (BW) (Fig. 6), ovary weight (OW) (Fig. 7), the equation obtained was as follows:

$$
\begin{aligned}
& F+T L \quad y=-11545+1066 x ; \quad r=0.64 \\
& \mathrm{~F}+\mathrm{BW} \quad \mathrm{y}=-62418+2402 \mathrm{x} ; \mathrm{r}=0.87 \\
& \mathrm{~F}+\mathrm{OW} \quad \mathrm{y}=-11494+13 \mathrm{x} ; \quad \mathrm{r}=0.99
\end{aligned}
$$


In all the reactions the coefficient of correlation (r) was significant at $0.01 \%$ level. The lowest (r) was with length (0.64) while the highest was with ovary weight $(0.99)$ and with body weight ( 0.87$)$.

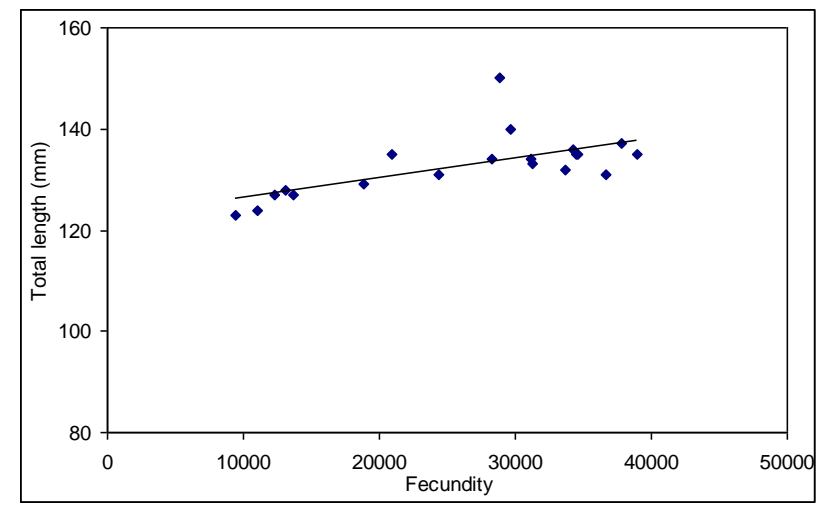

Fig. 5. Relation between fecundity and total length of C. auratus

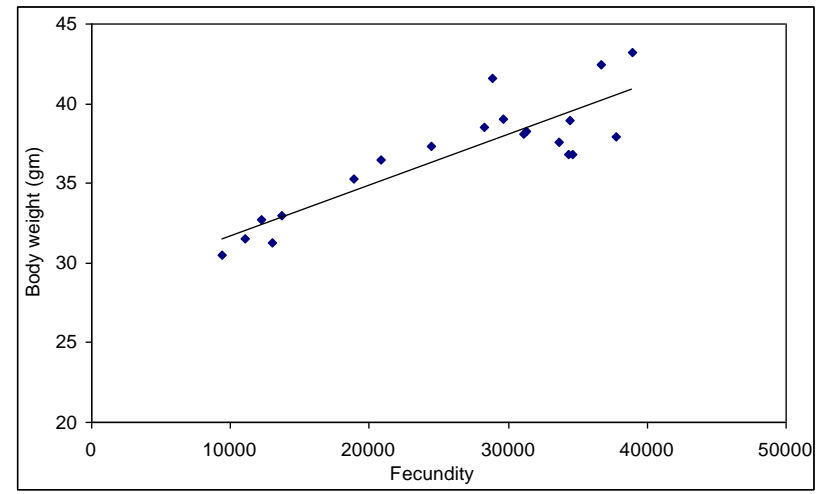

Fig. 6. Relation between fecundity and body weight of $C$. auratus

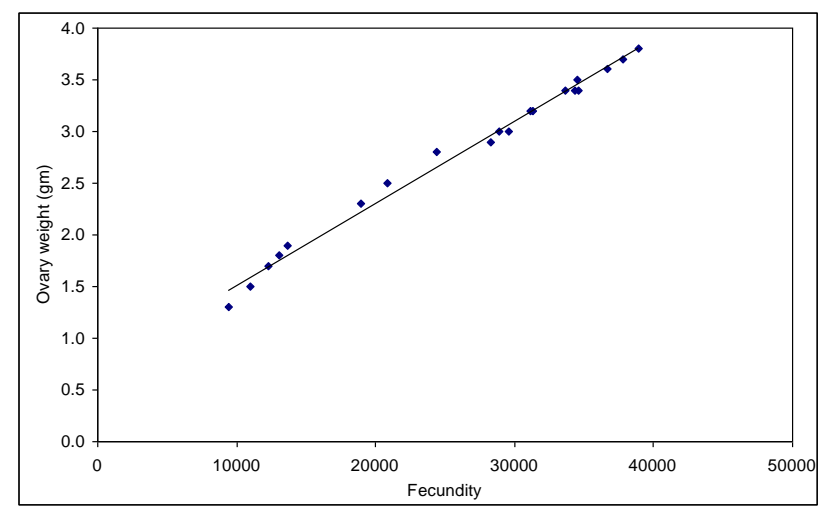

Fig. 7. Relation between fecundity and ovary weight of C. auratus

\subsection{Sex Ratio}

Sex of adults of both males and females were easy to determine by their external characters. In males, the cloacal aperture is concave and anal fin remains forked, while in females cloacal aperture is convex and anal fin remains as a bunch of fin rays. At the time of sexual maturity male goldfish develops breeding tubercles, white raised spots on their gill covers and along the first ray of their pectoral fins, while in females no sign of breeding tubercles were found. Out of 428 specimens, the percentage of male and female were 41.38 : 58.62. The females were predominating throughout the months. The chi-square value $(0.384)$ of male and female indicates insignificance at both $0.5 \%$ and $0.1 \%$ level of significance. 




Fig. 8. Monthly collection of male and female of C. auratus

Fig. 8 represents data on monthly collection of male and female of $C$. auratus. In this study, the occurrence of huge number of females of $C$. auratus was in December, January, February and November concludes that the spawning period is from November to March and is a single breeder. While working in East Hammar Marsh, Southern Iraq it has been found that fish in maturity stage began to appear in the catch during the period from December to July while no fish was caught during August to November [2]. According to him ripe fish were found during January to May and were most common in January (53.8\%). In our findings mature females were found from October to March. The mean GSI in our study for 12 months was from 2.43 (September) to 8.0 (December) while study of [2] found GSI from 1.02 (September) to 8.94 (February). We found from the result of reproductive periodicity that $C$. auratus is a single breeder and the breeding period is from November to March. In studies in the Tharthar Arm and Tigris River it has been determined that spawning period of $C$. carassius occurred from May to July [6]. It has been observed that many species of multiple spawning fish have a rhythmic periodicity of reproductive behavior [12]. [13] determined that spawning of $C$. carassius in Marmara Lake occurred from April to July and the spawning of C. gibelio in the south was from March to August in Agion Region (Aydin-Turkey) and suggested that it is multiple spawned [1]. [6] stated that fecundity of $C$. carassius varied from a mean of 19470 to 95232 per female at length between 139 and $260 \mathrm{~mm}$ respectively in Tharthar Arm and Tigris River. The fecundity of C. gibelio in Amur Reservoir varies from 160,000 to 383,000 , averaging 254,000 eggs [14]. Although [13] reported that maximum of fecundity was 380,000 eggs/female; maximum egg diameter of $C$. carassius population living in Marmara Lake (Turkey) was $1.229 \mathrm{~mm}$. From our experiment we found 9386 to 38950 eggs/female having total length 123 to $150 \mathrm{~mm}$ and body weight 30.5 to $43.2 \mathrm{gm}$. Fecundity was affected by age, size, species, feeding of fish, season and environmental condition, as well as between populations of the same species and did not remain constant from year to year [15]. In this present study, the predominance of females in 12 months catches which was in a close agreement with observation of [16].

\section{Conclusion}

As in our country, goldfish is an imported fish and it costs a lot of money each year importing ornamental fish to meet up the demand of the aesthetic minded people as well as the requirement of the country. So it is necessary to know about the culture of this fish in freshwater condition. For this reason, this research is worked done about different reproductive aspects of $C$. auratus.

\section{Acknowledgments}

The authors express their gratitude to Mr. Md. Mozammel Haque, Director, BCSIR Laboratories, Rajshahi for providing all research facilities. The authors also express their sincere thanks to Chairman, BCSIR Dhaka, for his kind Co-operation.

\section{References}

[1] H. Sasi, The length and weight relations of some reproduction characteristics of Prussian Carp, Carassius gibelio (Bloch, 1782) in the south Aegean Region (Aydin-Turkey), Turk. J. Fish. Aquat. Sci., 8, 2008, 87-92.

[2] S.S. Al-Noor, Population Status of Gold Fish Carassius auratus in Restored East Hammar Marsh, Southern Iraq, JKAU: Mar. Sci., 21(1), 2010, 65-83.

[3] Z. Mahmud, F. Ahmed, A.K. Ghosh, M.A.K. Azad, J. Bir and S. M. B. Rahman, Induced breeding, embryonic and larval development of comet gold fish (Carassius auratus) in Khulna, Bangladesh, Int. J. Biosci., 2:10(2), 2012, 28-38.

[4] A.A.O. Salas and H.R. Bustamante, Fecundity, survival, and growth of the seahorse Hippocampus ingens (Pisces: Syngnathidae) under semi-controlled conditions, Int. J. Trop. Biol., 54(4), 2006, 1099-1102.

[5] R.E. Spieler, T.A. Noeske, V. de Vlaming and A.H. Meier, Effects of thermocycles on body weight gain and gonadal growth in the goldfish Carassius auratus Trans, Am. Fish. Soc., 106, 1977, 440-444.

[6] A.O. Shawardi, Ecology and Biology of Crucian Carp Carassius carassius (L.1758) and Khishini Liza abu (Heck in Tharthar Arm and Tigris River, doctoral diss., College of Science, Al-Mustansiriya University, 2006. 142 p. 
[7] M. Tsoumani, R. Liasko, P. Moutsaki, I. Kagalou and I. Leonardos, Length-Weight relationships of an invasive cyprinid fish (Carassius giblio) from 12 Greek lakes in relation to their trophic states, J. Appl. Ichthyol., 22, 2006, 281-284.

[8] M. Peňáz, P. Ráb and M. Prokeš, Cytological analysis, gynogenesis and early development of Carassius auratus gibelio, Acta Scientiarum Naturalum Academiae Scientiarum Bohemoslovacae- Brno., 13, 1979, 1-33.

[9] T. Banegal, Methods for Assessment of Fish Production in Freshwaters, IBP. Handbook, 3 (London: Blackwell Scientific Publications, 1978) 75-102.

[10] K.F. Lagler, The Ecology of Fishes, (Translated by L. Birkett), (London: Academic Press, 1966) 317.

[11] A.L. Hickling and E. Rutenberg, The ovary as an indicator of the spawning period in fishes, J. mar. biol. Ass. U.K., 22, 1936. 405408.

[12] L.A. McEnvoy and J. McEnvoy, Multiple Spawning of Several Commercial Fish Species and its Consequences for Fisheries Management, Cultivation and Experimentation, J. Fish. Biol., 41, 1992, 125-136.

[13] S. Balik, R. Ustaoglu and H.M. Sari, Marmara Gölü’ndeki (Salihli) Carassius carassius L., 1758 Populasyonunun Biyo-Ekolojik Özelliklerinin İncelenmesi, Ege Universitesi, Su Ürünleri Sempozyumu, İzmir., 33, 1991, 43-56.

[14] L.S. Berg, Freshwater Fisher of the USSR and Adjacent Countries, Academy of Sciences of the USSR, (Translated From Russian, Israel Program for Scientific Translations, 1949), 2 (Jerusalem: $4^{\text {th }}$ Edition, 1964) 496.

[15] G.V. Nikolsky, Theory of Fish Population Dynamics. (Koenigstein: Otto Science Publishers, 1969$) 317$.

[16] M. Peňáz, and A. Dulmaa, Morphology, population structure, reproduction and growth in Mongolian populations of Carassius auratus gibelio (Pisces: Cyprinidae), Folia Zoologica., 36, 1987, 161-173.

Table 1. Total length (TL), total body weight (BW), total ovary weight $(\mathrm{OW})$, number of ova in $100 \mathrm{mg}$ and estimated number of ova

\begin{tabular}{|c|c|c|c|c|c|}
\hline No. & TL $(\mathrm{mm})$ & BW $(\mathrm{g})$ & OW $(\mathrm{g})$ & $\begin{array}{c}\text { No. of ova in } \\
100 \mathrm{mg}\end{array}$ & $\begin{array}{c}\text { Estimated no. } \\
\text { of ova }\end{array}$ \\
\hline 1 & 123 & 30.5 & 1.3 & 722 & 9386 \\
\hline 2 & 124 & 31.5 & 1.5 & 735 & 11025 \\
\hline 3 & 127 & 32.7 & 1.7 & 721 & 12257 \\
\hline 4 & 127 & 33.0 & 1.9 & 719 & 13661 \\
\hline 5 & 129 & 35.3 & 2.3 & 822 & 18906 \\
\hline 6 & 135 & 36.5 & 2.5 & 835 & 20875 \\
\hline 7 & 131 & 37.3 & 2.8 & 872 & 24416 \\
\hline 8 & 135 & 38.9 & 3.5 & 985 & 34475 \\
\hline 9 & 134 & 38.1 & 3.2 & 972 & 31104 \\
\hline 10 & 132 & 37.6 & 3.4 & 989 & 33626 \\
\hline 11 & 133 & 38.3 & 3.2 & 978 & 31296 \\
\hline 12 & 140 & 39.0 & 3.0 & 987 & 29610 \\
\hline 13 & 136 & 36.8 & 3.4 & 1009 & 34306 \\
\hline 14 & 137 & 37.9 & 3.7 & 1021 & 37777 \\
\hline 15 & 135 & 36.8 & 3.4 & 1018 & 34612 \\
\hline 16 & 134 & 38.5 & 2.9 & 975 & 28275 \\
\hline 17 & 135 & 43.2 & 3.8 & 1025 & 38950 \\
\hline 18 & 131 & 42.4 & 3.6 & 1018 & 36648 \\
\hline 19 & 150 & 41.6 & 3.0 & 962 & 28860 \\
\hline 20 & 128 & 31.3 & 1.8 & 725 & 13050 \\
\hline
\end{tabular}

